\title{
PENERAPAN METODE CERTAINTY FACTOR PADA SISTEM PAKAR DIAGNOSIS PENYAKIT DAN HAMA TANAMAN MANGGIS
}

\author{
Farha Fitrahul Janah ${ }^{1}$, Gibtha Fitri Laxmi ${ }^{2}$, Freza Riana ${ }^{3}$ \\ Program Studi Teknik Informatika, Fakultas Teknik dan Sains \\ Universitas Ibn Khaldun Bogor \\ Jl. Sholeh Iskandar Km. 2, Kota Bogor \\ Farhafz123@gmail.com ${ }^{1}$, gibtha.fitri.laxmi@ft.uika-bogor.ac.id ${ }^{2}$, freza@ ft.uika-bogor.ac.id ${ }^{3}$
}

\begin{abstract}
Abstrak
Tanaman manggis merupakan salah satu komoditas hortikultura buah-buahan tropis asli indonesia dan bernilai ekonomis tinggi serta mempunyai prospek cerah untuk diusahakan. Salah satu kendala dalam budidaya manggis adalah rendahnya kualitas buah yang disebabkan oleh serangan OPT. Umumnya upaya dalam mencegah dan menanggulangi penyebaran penyakit dan hama pada tanaman manggis adalah berkonsultasi dengan pakar, namun keterbatasan yang menjadi kendala adalah terbatasnya ketersediaan pakar dalam suatu daerah. Melihat permasalahan tersebut maka pada penelitian kali ini dibuatlah sistem pakar berbasis website untuk mendiagnosis penyakit dan hama pada tanaman manggis dengan menerapkan metode Certainty Factor. Terdapat 5 penyakit dan 5 hama dengan 42 gejala, diantaranya 25 gejala pada penyakit dan 17 gejala pada hama yang dapat diidentifikasi dalam sistem pakar ini. Didapatkan nilai persentase sebesar $80 \%$ untuk hasil perbandingan diagnosis pakar dengan diagnosis sistem menggunakan metode Certainty Factor. Nilai tersebut diperoleh berdasarkan kesesuaian dari 50 data uji yang dibuat secara acak. Sistem pakar ini dapat membantu petani manggis dan masyarakat dalam mendiagnosis penyakit dan hama pada tanaman manggis.
\end{abstract}

Kata kunci : Certainty Factor, Hama, Penyakit, Sistem Pakar, Tanaman Manggis

\section{Abstract}

Mangosteen is one of the horticultural commodities of Indonesian original tropical fruits and has either high value or prospects for cultivation. One of the obstacles in mangosteen cultivation is the low quality of the fruit caused by pests. In general, one of the efforts to prevent and control the spread of diseases and pests in mangosteen plants is to consult with the expert, however this can be an obstacle due to the limited number of experts in an area. Referring to this problem, in this study, a website-based expert system was created to diagnose diseases and pests in mangosteen plants by applying the Certainty Factor method. There were 5 diseases and 5 pests with 42 symptoms, including 25 symptoms of diseases and 17 symptoms of pests that can be identified by this expert system. The percentage value obtained was $80 \%$ for the comparison between expert diagnoses and system diagnoses using the Certainty Factor method. This value was obtained based on the suitability of 50 test data that were randomly generated. This expert system can helps mangosteen farmers and the community in diagnosing diseases and pests in mangosteen plants.

Keywords : Certainty Factor, Disease, Expert System, Mangosteen Plant, Pest

\section{Pendahuluan}

Manggis di luar negeri dikenal sebagai "Queen of Fruits" karena memiliki keistimewaan dan kelezatan rasa yang unik yaitu manis, asam dan menyegarkan, serta memiliki nilai gizi yang tinggi (Muslim, 2011). Tanaman manggis di Indonesia merupakan warisan dari leluhur dan telah berumur puluhan tahun (Firdaus, 2011). Salah satu kendala dalam budi daya manggis adalah rendahnya kualitas buah manggis yang dihasilkan. Rendahnya kualitas buah tersebut disebabkan oleh banyak faktor seperti serangan Organisme Pengganggu Tumbuhan (OPT), serta relatif kecilnya ukuran buah (Anwarudin, 2016). Menurut pengamatan secara visual di lapangan,

Farha Fitrahul Janah, Gibtha Fitri Laxmi, Freza Riana 
menunjukkan bahwa burik pada kulit buah manggis cukup serius dalam menurunkan kualitas buah karena persentase dan intensitas lebih dari $40 \%$. Burik pada buah manggis disebabkan karena adanya hama yang memakan/menggerogoti kulit buah manggis sehingga kulit manggis terlihat kusam dan tidak mulus (Anwarudin, 2016).

Untuk menanggulangi serangan penyakit dan hama pada tanaman manggis, petani manggis membutuhkan seseorang yang ahli dalam bidang tersebut agar risiko gagal panen dapat ditekan seminimal mungkin. Namun terdapat banyak keterbatasan yang menjadi kendala bagi petani seperti tidak tersedianya seorang pakar di setiap daerah. Dalam hal ini sistem pakar dihadirkan sebagai salah satu cara untuk memecahkan permasalahan setelah seorang pakar (Hayadi, 2016). Dengan harapan sistem ini dapat digunakan untuk mengurangi atau memperkecil risiko gagal panen yang diakibatkan oleh OPT, serta dapat diakses oleh petani manggis dan masyarakat luas. Sistem pakar (expert system) biasa disebut dengan knowledge base system yaitu suatu aplikasi komputer yang ditujukan untuk membantu pengambilan keputusan atau pemecahan persoalan dalam bidang yang spesifik (Hayadi, 2016). Pada penelitian sistem pakar ini menggunakan metode Certainty Factor.

Certainty Factor (Faktor Kepastian) menyatakan kepercayaan dalam sebuah kejadian (fakta atau hipotesa) berdasarkan bukti atau penilaian pakar. Certainty Factor memperkenalkan konsep kepercayaan dan ketidakpercayaan (Kusrini, 2008). Penelitian tentang sistem pakar telah banyak diteliti pada penelitian sebelumnya. Seperti penelitian yang dilakukan oleh (Fanny, Hasibuan dan Buulolo, 2017) yang menggunakan metode Certainty Factor dengan penelusuran Forward Chaining dengan tujuan mendiagnosis penyakit asidosis tubulus renalis berdasarkan gejala yang dirasakan oleh pasien, pada penelitian ini memiliki tingkat kepercayaan sebesar $85 \%$. Pada beberapa penelitian yang menggunakan metode Certainty Factor menyatakan bahwa metode ini merupakan metode yang cukup baik dalam mendiagnosis suatu penyakit pada manusia maupun tumbuhan (Saputri $d k k ., 2020$ ).

\section{Tinjauan Pustaka}

\section{II.1 Certainty Factor}

Teori Certainty Factor (CF) diperkenalkan oleh Shortliffe dan Buchanan dalam pembuatan MYCIN untuk mengakomodasi ketidakpastian pemikiran (inexact reasoning) seorang pakar. Certainty Factor menggunakan suatu nilai untuk menggambarkan derajat keyakinan seorang pakar terhadap suatu permasalahan (Fanny, Hasibuan dan Buulolo, 2017).

Bentuk dasar rumus Certainty Factor sebuah aturan adalah seperti ditunjukkan oleh persamaan berikut:

$$
\begin{aligned}
& \mathrm{CF}(\mathrm{H}, \mathrm{E})=\mathrm{MB}(\mathrm{H}, \mathrm{E})-\mathrm{MD}(\mathrm{H}, \mathrm{E}) \\
& \mathrm{CF}(\mathrm{H}, \mathrm{e})=\mathrm{CF}(\mathrm{E}, \mathrm{e}) \times \mathrm{CF}(\mathrm{H}, \mathrm{E}) \\
& \text { CFCombine }=\mathrm{CF} 1+(\mathrm{CF} 2 \times(1-\mathrm{CF} 1))
\end{aligned}
$$

Keterangan :

$\mathrm{CF}(\mathrm{E}, \mathrm{e})$ : $C F$ evidence $\mathrm{E}$ yang dipengaruhi oleh evidence $e$ (nilai bobot dari seorang pakar).

$\mathrm{CF}(\mathrm{H}, \mathrm{E})$ : $C F$ hipotesis dengan asumsi evidence diketahui dengan pasti, yaitu ketika $\mathrm{CF}(\mathrm{E}, \mathrm{e})=1$ (nilai bobot dari user).

MB(H,E) : Ukuran kenaikan kepercayaan (measure of increased belief) terhadap hipotesis $\mathrm{H}$ yang dipengaruhi oleh gejala $\mathrm{E}$.

$\mathrm{MD}(\mathrm{H}, \mathrm{E})$ : Ukuran kenaikan ketidakpercayaan (measure of increased disbelief) terhadap hipotesis $\mathrm{H}$ yang dipengaruhi oleh gejala $\mathrm{E}$.

$\mathrm{CF}(\mathrm{H}, \mathrm{e}): C F$ hipotesis yang dipengaruhi oleh evidence $e$. Jika semua evidence pada antecedent diketahui dengan pasti.

\section{II.2 Tanaman Manggis}

Manggis merupakan salah satu ciri khas buah Asia Tenggara, Tanaman manggis di Indonesia sebagian besar merupakan warisan leluhur yang telah berumur puluhan tahun (Firdaus, 2011). Manggis merupakan tanaman yang pertumbuhannya paling lambat tetapi umurnya paling panjang diantara tanaman buah tropika lainnya (Anwarudin, 2016).

\section{II.3 Sistem Pakar}

Sistem pakar adalah sebuah sistem yang kinerjanya mengadopsi keahlian yang dimiliki oleh seorang pakar dalam bidang tertentu ke dalam computer yang disajikan dengan tampilan yang dapat digunakan oleh pengguna yang bukan seorang pakar sehingga dengan sistem tersebut pengguna dapat

Farha Fitrahul Janah, Gibtha Fitri Laxmi, Freza Riana 
membuat sebuah keputusan atau menentukan kebijakan layaknya seorang pakar (Andriani, 2016).

\section{Analisis dan Perancangan}

\section{III.1 Analisis dan Pengolahan}

Pada tahap ini dilakukan analisis kebutuhan sistem, seperti analisis sistem yang akan diusulkan, pembuatan tabel basis pengetahuan berdasarkan data peyakit dan hama serta data gejala yang telah didapat, dan penerapan metode Certainty Factor.

\section{Analisis Sistem Yang Diusulkan}

Analisis sistem yang diusulkan merupakan gambaran mengenai sistem baru yang akan dibuat. Analisis sistem yang diusulkan berguna agar perancangan sistem dapat terarah kepada fungsifungsi utama. Analisis sistem yang diusulkan dapat dilihat pada Gambar III.1.

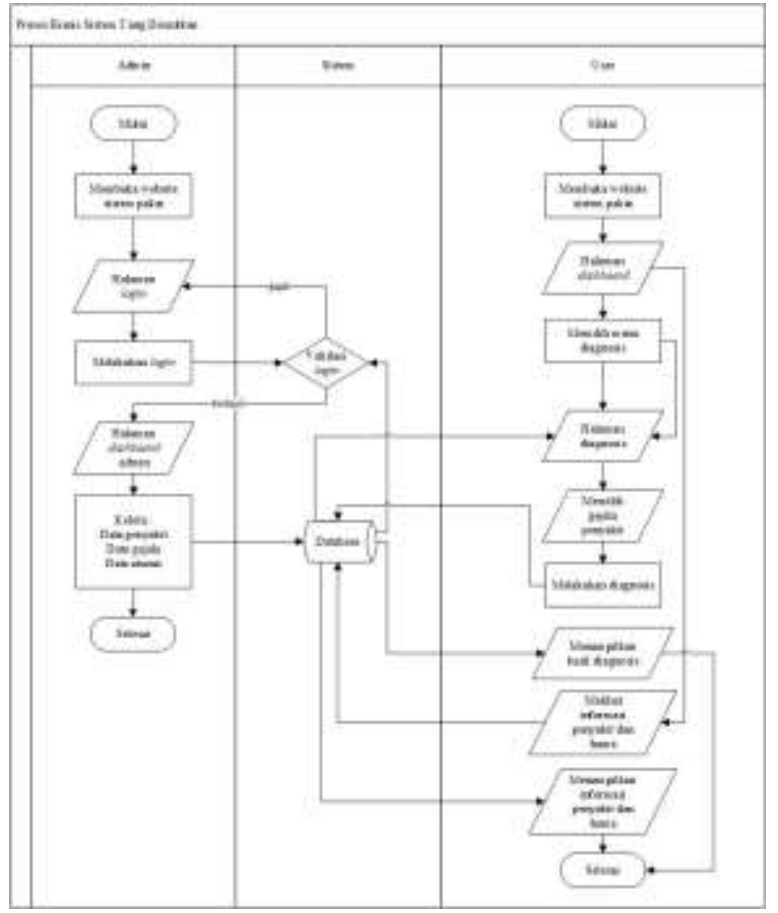

Gambar III.1 Analisis Sistem Yang Diusulkan

\section{Basis Pengetahuan}

Pada penelitian ini data yang dikumpulkan didapatkan dari seorang pakar penyakit dan hama tanaman manggis yang bekerja di Balai Penelitian Buah Tropika Solok. Data yang diperoleh dapat dilihat pada Tabel III.1.
Tabel III.1 Data Penyakit, Hama dan Gejala

\begin{tabular}{|c|c|c|c|}
\hline KP & Nama & KG & Nama Gejala \\
\hline \multirow{5}{*}{$\mathrm{P} 01$} & \multirow{5}{*}{$\begin{array}{l}\text { Busuk } \\
\text { Buah }\end{array}$} & G01 & $\begin{array}{l}\text { Kulit buah tampak kehitaman dan } \\
\text { mengkilat }\end{array}$ \\
\hline & & G02 & Kulit buah berwarna \\
\hline & & G03 & $\begin{array}{l}\text { Buah manggis matang membusuk } \\
\text { setelah dipetik dari pohon }\end{array}$ \\
\hline & & G04 & $\begin{array}{l}\text { Warna kulit tangkai dan pangkal } \\
\text { buah berubah kehitaman }\end{array}$ \\
\hline & & G05 & $\begin{array}{l}\text { Perubahan warna kulit buah } \\
\text { meluas ke seluruh area buah }\end{array}$ \\
\hline \multirow{8}{*}{$\mathrm{P} 02$} & \multirow{8}{*}{$\begin{array}{l}\text { Kanker } \\
\text { Batang }\end{array}$} & G06 & $\begin{array}{l}\text { Kulit batang atau cabang menjadi } \\
\text { kering }\end{array}$ \\
\hline & & G07 & Daun menjadi pucat \\
\hline & & G08 & $\begin{array}{l}\text { Batang atau cabang yang terserang } \\
\text { mengeluarkan getah }\end{array}$ \\
\hline & & G09 & $\begin{array}{l}\text { Warna kulit batang atau cabang } \\
\text { berubah }\end{array}$ \\
\hline & & G10 & $\begin{array}{l}\text { Tanaman cepat berbunga dan } \\
\text { bunga tidak normal }\end{array}$ \\
\hline & & G11 & $\begin{array}{l}\text { Menghasilkan buah yang tidak } \\
\text { normal }\end{array}$ \\
\hline & & G12 & Daun mengering dan rontok \\
\hline & & G13 & $\begin{array}{l}\text { Getah menggumpal dan } \\
\text { mendominasi dibawah kulit batang }\end{array}$ \\
\hline \multirow{4}{*}{$\mathrm{P} 03$} & \multirow{4}{*}{$\begin{array}{l}\text { Busuk } \\
\text { Akar }\end{array}$} & G14 & $\begin{array}{l}\text { Terdapat (jamur akar merah / } \\
\text { jamur akar putih / jamur akar } \\
\text { cokelat) pada akar tanaman }\end{array}$ \\
\hline & & G15 & $\begin{array}{l}\text { Terdapat titik-titik hitam pada } \\
\text { permukaan kayu akar jika kulit } \\
\text { akar dikupas }\end{array}$ \\
\hline & & G16 & Daun menguning dan layu \\
\hline & & G12 & Daun mengering dan rontok \\
\hline \multirow{2}{*}{ P04 } & \multirow{2}{*}{$\begin{array}{l}\text { Jamur } \\
\text { Upas }\end{array}$} & G17 & $\begin{array}{l}\text { Terdapat Jamur membentuk } \\
\text { miselium mengkilat seperti perak }\end{array}$ \\
\hline & & G18 & Jamur berkembang menjadi kerak \\
\hline
\end{tabular}

Farha Fitrahul Janah, Gibtha Fitri Laxmi, Freza Riana 


\begin{tabular}{|c|c|c|c|}
\hline $\mathbf{K P}$ & Nama & $\mathbf{K G}$ & Nama Gejala \\
\hline & & & merah jambu \\
\hline & & G19 & Cabang tanaman mati \\
\hline \multirow{7}{*}{ P05 } & \multirow{7}{*}{$\begin{array}{l}\text { Bercak } \\
\text { Daun }\end{array}$} & G12 & Daun mengering dan rontok \\
\hline & & $\mathrm{G} 20$ & $\begin{array}{l}\text { Adanya bercak tidak beraturan } \\
\text { pada daun }\end{array}$ \\
\hline & & $\mathrm{G} 21$ & $\begin{array}{l}\text { Bercak daun berwarna kelabu atau } \\
\text { cokelat }\end{array}$ \\
\hline & & $\mathrm{G} 22$ & $\begin{array}{l}\text { Bercak daun dimulai dengan } \\
\text { mengeringnya bagian ujung }\end{array}$ \\
\hline & & $\mathrm{G} 23$ & $\begin{array}{l}\text { Bercak Menjalar pada bagian } \\
\text { pinggiran daun }\end{array}$ \\
\hline & & G24 & $\begin{array}{l}\text { Bercak berkembang hingga daun } \\
\text { menggulung }\end{array}$ \\
\hline & & G25 & $\begin{array}{l}\text { Hitam pada sisi atas dan bawah } \\
\text { daun }\end{array}$ \\
\hline
\end{tabular}

\begin{tabular}{|c|c|c|c|}
\hline $\mathbf{K P}$ & Nama & $\mathbf{K G}$ & Nama Gejala \\
\hline & & & keperakan \\
\hline & & G37 & $\begin{array}{l}\text { Terdapat garis fases di tengah } \\
\text { korokan }\end{array}$ \\
\hline & & G38 & $\begin{array}{l}\text { Daun menjadi kering dan berwarna } \\
\text { cokelat }\end{array}$ \\
\hline & & G39 & Daun mengecil dan mengkerut \\
\hline & & G40 & Menyisakan tulang-tulang daun \\
\hline \multirow{2}{*}{ H05 } & \multirow{2}{*}{$\begin{array}{l}\text { Kutu } \\
\text { Putih }\end{array}$} & G41 & $\begin{array}{l}\text { Terjadi kerontokan pada buah yang } \\
\text { masih muda }\end{array}$ \\
\hline & & G42 & $\begin{array}{l}\text { Ada embun berwarna hitam } \\
\text { menutupi permukaan buah }\end{array}$ \\
\hline
\end{tabular}

\section{Penerapan Metode Certainty Factor}

Algoritma metode Certainty Factor yang digunakan dalam penelitian ini digambarkan pada Gambar III.2

\begin{tabular}{|c|c|c|c|}
\hline \multirow{3}{*}{ H01 } & \multirow{3}{*}{ Thrips } & G26 & $\begin{array}{l}\text { Menampakan gejala burik, kulit } \\
\text { buah berwarna keperakan, atau } \\
\text { kuning pucat hingga kecoklatan }\end{array}$ \\
\hline & & G27 & $\begin{array}{l}\text { Adanya luka yang memanjang dan } \\
\text { mengeras menutupi permukaan } \\
\text { buah }\end{array}$ \\
\hline & & G28 & $\begin{array}{l}\text { Adanya spot-spot putih yang } \\
\text { berpencar pada buah manggis }\end{array}$ \\
\hline \multirow{4}{*}{$\mathrm{H} 02$} & \multirow{4}{*}{$\begin{array}{c}\text { Babi } \\
\text { Hutan }\end{array}$} & G29 & Tanaman muda akan tumbang \\
\hline & & G30 & $\begin{array}{l}\text { Perakaran rusak dan daun menjadi } \\
\text { layu serta kering }\end{array}$ \\
\hline & & G31 & Pohon lama-kelamaan akan mati \\
\hline & & G32 & Kulit batang terkelupas \\
\hline \multirow{2}{*}{ H03 } & \multirow{2}{*}{ Tupai } & G33 & $\begin{array}{l}\text { Terdapat bekas luka gigitan pada } \\
\text { buah manggis }\end{array}$ \\
\hline & & G34 & $\begin{array}{l}\text { Banyak buah yang jatuh atau } \\
\text { rontok kepermukaan tanah }\end{array}$ \\
\hline \multirow{2}{*}{ H04 } & \multirow{2}{*}{$\begin{array}{c}\text { Ulat } \\
\text { Pengorok } \\
\text { Daun }\end{array}$} & G35 & $\begin{array}{l}\text { Bekas korokan larva yang sangat } \\
\text { khas }\end{array}$ \\
\hline & & G36 & $\begin{array}{l}\text { Pada daun terdapat korokan } \\
\text { berkelok-kelok berwarna putih }\end{array}$ \\
\hline
\end{tabular}

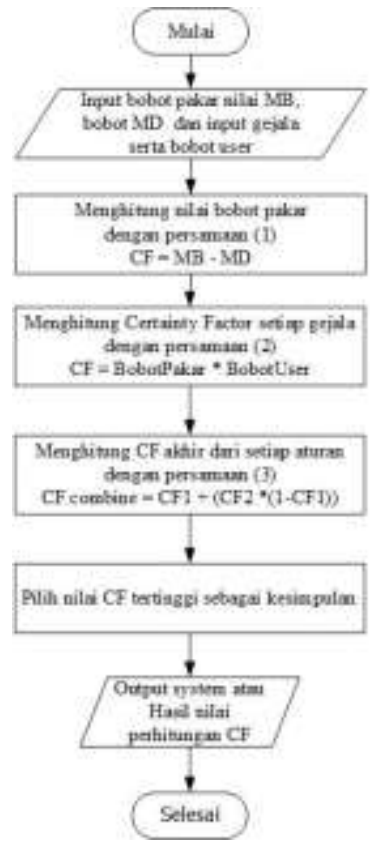

Gambar III.2 Algoritma Metode Certainty Factor

Tabel penilaian adalah tabel mengenai keterkaitan tentang bobot user. Adapun tabel penilaian dapat di lihat pada Tabel III.2.

Farha Fitrahul Janah, Gibtha Fitri Laxmi, Freza Riana 
Tabel III.2 Tabel Standar Bobot Penilaian (Arifin, Eka dan Retnani, 2017)

\begin{tabular}{cl}
\hline Bobot User & Frase \\
\hline 0,2 & Tidak Yakin \\
\hline 0,4 & Kurang Yakin \\
\hline 0,6 & Cukup Yakin \\
\hline 0,8 & Yakin \\
\hline 1 & Sangat Yakin \\
\hline
\end{tabular}

Berikut contoh perhitungan dari beberapa gejala yang dipilih. Masing-masing penyakit dan gejala akan dihubungkan dengan nilai kepercayaan yang diperoleh dari seorang pakar pada saat pengumpulan data seperti tabel III.3.

Tabel III.3 Contoh Nilai Kepercayaan Dari Pakar Dan User

\begin{tabular}{|c|c|c|c|c|}
\hline $\begin{array}{l}\text { Penyakit } \\
\text { Terpilih }\end{array}$ & $\begin{array}{l}\text { Gejala } \\
\text { Terpilih }\end{array}$ & $\begin{array}{l}\text { CF } \\
\text { MB } \\
\text { MD }\end{array}$ & $\begin{array}{c}=\text { Bobot } \\
-\quad \text { User }\end{array}$ & CF \\
\hline \multirow{3}{*}{$\begin{array}{l}\text { Kanker } \\
\text { Batang }\end{array}$} & $\begin{array}{l}\text { Daun menjadi } \\
\text { pucat }\end{array}$ & 0,4 & 0,8 & 0,32 \\
\hline & $\begin{array}{l}\text { Warna kulit } \\
\text { batang atau } \\
\text { cabang berubah }\end{array}$ & 0,5 & 0,8 & 0,4 \\
\hline & $\begin{array}{l}\text { Getah } \\
\text { menggumpal } \\
\text { dan } \\
\text { mendominasi } \\
\text { dibawah kulit } \\
\text { batang }\end{array}$ & 0,6 & 0,8 & 0,48 \\
\hline $\begin{array}{c}\text { Busuk } \\
\text { Akar }\end{array}$ & $\begin{array}{l}\text { Terdapat titik- } \\
\text { titik hitam pada } \\
\text { permukaan kayu } \\
\text { akar jika kulit } \\
\text { akar dikupas }\end{array}$ & 0,5 & 0,8 & 0,4 \\
\hline
\end{tabular}

Langkah terakhir adalah mengkombinasikan nilai $\mathrm{CF}$ dari masing-masing rule. Berikut adalah perhitungan kombinasi $\mathrm{CF}$ untuk penyakit 1 atau penyakit kanker batang dengan rumus persamaan seperti berikut :

CFCombine $=$ CF1 $+($ CF2 $\times(1-$ CF1 $))$
CFCombineCF $(\mathrm{H}, \mathrm{E}) 1,2=\mathrm{CF} 1+(\mathrm{CF} 2 \times(1-\mathrm{CF} 1))$

$=0,32+(0,0,4 \times(1-0,32))$

$=0,592$ old

CFCombineCF(H,E)old, $3=$ CFold $+(\mathrm{CF} 3 \times(1-$ CFold))

$=0,592+(0,48 \times(1-0,592))$

$=0,78784$ old 2

Hasil Perhitungan akhir untuk penyakit kanker batang adalah 0.78784 atau $79 \%$. Selanjutnya melakukan perhitungan pada penyakit kedua yaitu penyakit busuk akar tahapan perhitungan sama seperti pada perhitungan penyakit pertama.

CFCombine $=$ CF1 $+($ CF2 $\times(1-$ CF1 $))$

$\mathrm{CFCombineCF}(\mathrm{H}, \mathrm{E}) 1,2=\mathrm{CF} 1+(\mathrm{CF} 2 \times(1-\mathrm{CF} 1))$

$=0+(0,4 \times(1-0))$

$=0,4$ old

Hasil Perhitungan akhir untuk penyakit busuk akar adalah 0.4 atau $40 \%$.

Dari gejala yang dipilih didapatkan nilai hasil diagnosis pada penyakit kanker batang sebesar $79 \%$ dan pada penyakit busuk akar sebesar $40 \%$. Maka hasil diagnosis menggunakan metode Certainty Factor adalah penyakit kanker batang.

\section{III.2 Perancangan Sistem}

Pada tahapan perancangan sistem terbagi menjadi 6 jenis tahapan, salah satunya adalah use case diagram yang menggambarkan urutan alur kerja sistem dan menghasilkan nilai yang dapat diukur untuk actor tertentu. Use case diagram dapat dilihat pada gambar III.3.

Farha Fitrahul Janah, Gibtha Fitri Laxmi, Freza Riana 


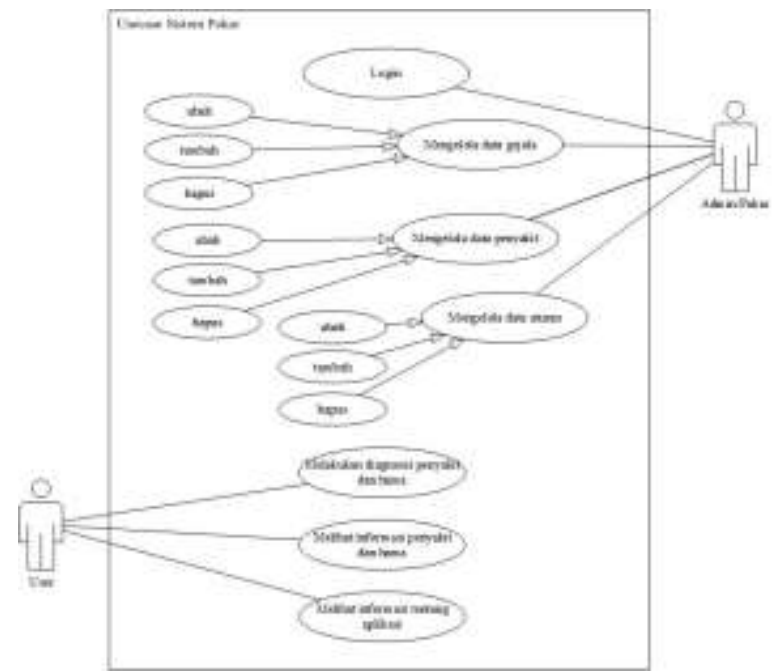

Gambar III.3 Use Case Diagram

\section{III.3 Implementasi Sistem}

Tahapan implementasi sistem yaitu tahapan implementasi dari desain antarmuka. Implementasi sistem pakar diagnosis penyakit dan hama tanaman manggis berbasis web dengan menuliskan baris code program menggunakan bahasa pemrograman PHP. Berikut merupakan tampilan ketika memilih gejala yang dapat dilihat pada Gambar III.4 dan untuk tampilan hasil diagnosis sistem berdasarkan gejalagejala yang dipilih dapat dilihat pada Gambar III.5.

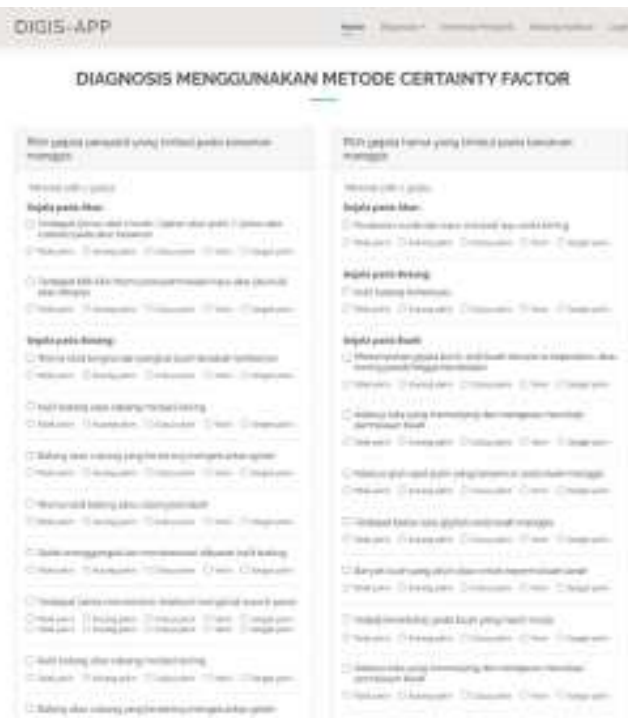

Gambar III.4 Halaman Diagnosis

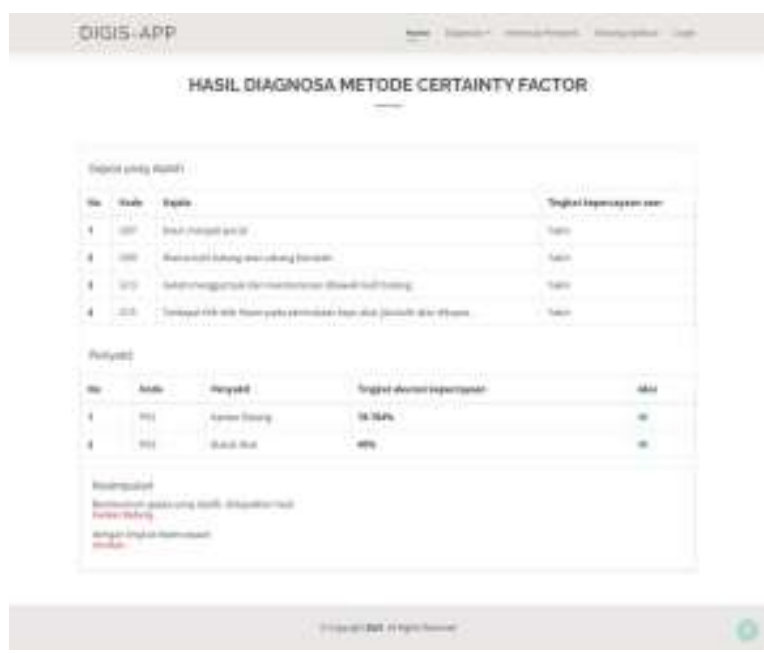

Gambar III.5 Halaman Hasil Diagnosis

\section{III.4 Pengujian Sistem}

Pengujian sistem dimaksudkan untuk pengujian tahapan sistem terhadap sistem yang telah dibangun. Pengujian yang dilakukan yaitu pengujian blackbox. Pengujian blackbox dilakukan untuk memvalidasi hasil yang dikeluarkan oleh sistem saat suatu perintah diberikan terhadap sistem.

\section{III.5 Evaluasi Sistem}

Evaluasi sistem dilakukan untuk mengetahui performa dari sistem pakar untuk memberikan hasil diagnosis penyakit tanaman manggis. Data uji simulasi berjumlah 50 sampel data yang diambil secara acak. Hasil rekomendasi yang diperoleh dari perhitungan sistem pakar dicocokkan dengan hasil analisa dari pakar. Hasil evaluasi sistem pakar dari 50 sampel yang telah diuji ditunjukkan pada Tabel III.4

Tabel III.4 Evaluasi Sistem

\begin{tabular}{|c|c|c|c|c|}
\hline \multirow{2}{*}{ No } & \multirow{2}{*}{ Gejala } & \multicolumn{2}{|c|}{ Hasil Diagnosis } & \multirow{2}{*}{ Validasi } \\
\hline & & Pakar & Sistem & \\
\hline 1. & $\begin{array}{l}\text { G14, G20, } \\
\text { G21, G24 }\end{array}$ & Bercak Daun & Bercak Daun & Sesuai \\
\hline 2. & $\begin{array}{l}\text { G07, G12, } \\
\text { G13, G19 }\end{array}$ & $\begin{array}{l}\text { Kanker } \\
\text { Batang }\end{array}$ & $\begin{array}{l}\text { Kanker } \\
\text { Batang }\end{array}$ & Sesuai \\
\hline 3. & $\begin{array}{l}\text { G02, G11, } \\
\text { G21, G22, } \\
\text { G23 }\end{array}$ & Bercak Daun & Bercak Daun & Sesuai \\
\hline
\end{tabular}

Farha Fitrahul Janah, Gibtha Fitri Laxmi, Freza Riana 


\begin{tabular}{|c|c|c|c|c|}
\hline \multirow{2}{*}{ No } & \multirow{2}{*}{ Gejala } & \multicolumn{2}{|c|}{ Hasil Diagnosis } & \multirow{2}{*}{ Validas } \\
\hline & & Pakar & Sistem & \\
\hline 4. & $\begin{array}{l}\text { G14, G15, } \\
\text { G16, G26, } \\
\text { G28 }\end{array}$ & Busuk Akar & Busuk Akar & Sesuai \\
\hline 5. & $\begin{array}{l}\text { G33, G36, } \\
\text { G37 }\end{array}$ & $\begin{array}{c}\text { Ulat } \\
\text { Penggorok } \\
\text { Daun }\end{array}$ & $\begin{array}{c}\text { Ulat } \\
\text { Penggorok } \\
\text { Daun }\end{array}$ & Sesuai \\
\hline 6. & $\begin{array}{l}\text { G22, G41, } \\
\text { G42 }\end{array}$ & Bercak Daun & Kutu Putih & $\begin{array}{l}\text { Tidak } \\
\text { Sesuai }\end{array}$ \\
\hline 7. & $\begin{array}{l}\text { G03, G04, } \\
\text { G05, G09 }\end{array}$ & Busuk Buah & Busuk Buah & Sesuai \\
\hline 8. & $\begin{array}{l}\text { G26, G27, } \\
\text { G28, G31, } \\
\text { G32 }\end{array}$ & Thrips & Babi Hutan & $\begin{array}{l}\text { Tidak } \\
\text { Sesuai }\end{array}$ \\
\hline 9. & $\begin{array}{l}\text { G34, G37, } \\
\text { G38, G40 }\end{array}$ & $\begin{array}{c}\text { Ulat } \\
\text { Penggorok } \\
\text { Daun }\end{array}$ & $\begin{array}{c}\text { Ulat } \\
\text { Penggorok } \\
\text { Daun }\end{array}$ & Sesuai \\
\hline 10. & $\begin{array}{l}\text { G18, G19, } \\
\text { G20, G21, } \\
\text { G23 }\end{array}$ & Bercak Daun & Jamur Upas & $\begin{array}{l}\text { Tidak } \\
\text { Sesuai }\end{array}$ \\
\hline 11. & $\begin{array}{l}\text { G06, G08, } \\
\text { G09, G12, } \\
\text { G13, G16 }\end{array}$ & $\begin{array}{l}\text { Kanker } \\
\text { Batang }\end{array}$ & $\begin{array}{l}\text { Kanker } \\
\text { Batang }\end{array}$ & Sesuai \\
\hline 12. & $\begin{array}{l}\text { G03, G04, } \\
\text { G05, G11 }\end{array}$ & Busuk Buah & Busuk Buah & Sesuai \\
\hline 13. & $\begin{array}{l}\text { G28, G26, } \\
\text { G27, G29 }\end{array}$ & Thrips & Babi Hutan & $\begin{array}{c}\text { Tidak } \\
\text { Sesuai }\end{array}$ \\
\hline 14. & $\begin{array}{l}\text { G35, G36, } \\
\text { G37, G38, } \\
\text { G41 }\end{array}$ & $\begin{array}{c}\text { Ulat } \\
\text { Penggorok } \\
\text { Daun }\end{array}$ & $\begin{array}{c}\text { Ulat } \\
\text { Penggorok } \\
\text { Daun }\end{array}$ & Sesuai \\
\hline 15. & $\begin{array}{l}\text { G20, G21, } \\
\text { G23, G25, } \\
\text { G16 }\end{array}$ & Bercak Daun & Bercak Daun & Sesuai \\
\hline 16. & $\begin{array}{l}\text { G01, G02, } \\
\text { G04, G05 }\end{array}$ & Busuk Buah & Busuk Buah & Sesuai \\
\hline 17. & $\begin{array}{l}\text { G17, G29, } \\
\text { G30, G31, } \\
\text { G32 }\end{array}$ & Babi Hutan & Babi Hutan & Sesuai \\
\hline 18. & $\begin{array}{l}\text { G14, G15, } \\
\text { G16, G17 }\end{array}$ & Busuk Akar & Busuk Akar & Sesuai \\
\hline
\end{tabular}

Hasil Diagnosis

No Gejala

Validasi

\section{Sistem}

\begin{tabular}{ll}
\hline G14, G15, & \\
G16, G12, Busuk Akar Busuk Akar & Sesuai \\
G07
\end{tabular}

$\begin{array}{ll}\text { 20. } \begin{array}{l}\text { G29, G32, } \\ \text { G30, G12, G11 }\end{array} & \text { Babi Hutan Babi Hutan Sesuai } \\ \text { G22, G23, } & \end{array}$

21. G24, G25, Bercak Daun Bercak Daun Sesuai G28

\begin{tabular}{|c|c|c|c|c|}
\hline 22. & $\begin{array}{l}\mathrm{G} 22, \mathrm{G} 25, \\
\mathrm{G} 24, \mathrm{G} 20, \\
\mathrm{G} 23, \mathrm{G} 31\end{array}$ & Bercak Daun & Bercak Daun & Sesuai \\
\hline 23. & $\begin{array}{l}\text { G08, G12, } \\
\text { G06, G40, } \\
\text { G35 }\end{array}$ & $\begin{array}{c}\text { Ulat } \\
\text { Penggorok } \\
\text { Daun }\end{array}$ & $\begin{array}{l}\text { Kanker } \\
\text { Batang }\end{array}$ & $\begin{array}{l}\text { Tidak } \\
\text { Sesuai }\end{array}$ \\
\hline 24. & $\begin{array}{l}\text { G26, G27, } \\
\text { G28, G21, } \\
\text { G22 }\end{array}$ & Thrips & Bercak Daun & $\begin{array}{l}\text { Tidak } \\
\text { Sesuai }\end{array}$ \\
\hline 25. & $\begin{array}{l}\text { G33, G26, } \\
\text { G27, G28 }\end{array}$ & Thrips & Tupai & $\begin{array}{l}\text { Tidak } \\
\text { Sesuai }\end{array}$ \\
\hline
\end{tabular}

G30, G31,
G01, G03, Busuk Buah Busuk Buah
G04, G05, Sesuai
G12

\begin{tabular}{|c|c|c|c|c|}
\hline 27. & $\begin{array}{l}\text { G38, G36, } \\
\text { G39, G40, } \\
\text { G16 }\end{array}$ & $\begin{array}{c}\text { Ulat } \\
\text { Penggorok } \\
\text { Daun }\end{array}$ & $\begin{array}{c}\text { Ulat } \\
\text { Penggorok } \\
\text { Daun }\end{array}$ & Sesuai \\
\hline 28. & $\begin{array}{l}\text { G30, G31, } \\
\text { G32, G40 }\end{array}$ & Babi Hutan & Babi Hutan & Sesuai \\
\hline 29. & $\begin{array}{l}\text { G03, G04, } \\
\text { G05, G08 }\end{array}$ & Busuk Buah & Busuk Buah & Sesuai \\
\hline 30. & $\begin{array}{l}\text { G17, G18, } \\
\text { G19, G12, } \\
\text { G20 }\end{array}$ & Jamur Upas & Jamur Upas & Sesuai \\
\hline 31. & $\begin{array}{l}\text { G32, G33, } \\
\text { G34 }\end{array}$ & Tupai & Tupai & Sesuai \\
\hline 32. & $\begin{array}{l}\text { G30, G31, } \\
\text { G32, G17, } \\
\text { G18, G19 }\end{array}$ & Jamur Upas & Jamur Upas & Sesuai \\
\hline
\end{tabular}

Farha Fitrahul Janah, Gibtha Fitri Laxmi, Freza Riana 


\begin{tabular}{|c|c|c|c|c|}
\hline \multirow{2}{*}{ No } & \multirow{2}{*}{ Gejala } & \multicolumn{2}{|c|}{ Hasil Diagnosis } & \multirow{2}{*}{ Validasi } \\
\hline & & Pakar & Sistem & \\
\hline 33. & $\begin{array}{l}\text { G14, G17, } \\
\text { G18, G19 }\end{array}$ & Jamur Upas & Jamur Upas & Sesuai \\
\hline 34. & $\begin{array}{l}\text { G14, G15, } \\
\text { G16, G12, } \\
\text { G36 }\end{array}$ & Busuk Akar & Busuk Akar & Sesuai \\
\hline 35. & $\begin{array}{l}\text { G09, G07, } \\
\text { G13, G15 }\end{array}$ & $\begin{array}{l}\text { Kanker } \\
\text { Batang }\end{array}$ & $\begin{array}{l}\text { Kanker } \\
\text { Batang }\end{array}$ & Sesuai \\
\hline 36. & $\begin{array}{l}\text { G06, G07, } \\
\text { G08, G17 }\end{array}$ & $\begin{array}{l}\text { Kanker } \\
\text { Batang }\end{array}$ & $\begin{array}{l}\text { Kanker } \\
\text { Batang }\end{array}$ & Sesuai \\
\hline 37. & $\begin{array}{l}\text { G05, G10, } \\
\text { G11, G12, } \\
\text { G13 }\end{array}$ & $\begin{array}{l}\text { Kanker } \\
\text { Batang }\end{array}$ & $\begin{array}{l}\text { Kanker } \\
\text { Batang }\end{array}$ & Sesuai \\
\hline 38. & $\begin{array}{l}\text { G16, G17, } \\
\text { G18, G19, } \\
\text { G20 }\end{array}$ & Jamur Upas & Jamur Upas & Sesuai \\
\hline 39. & $\begin{array}{l}\text { G27, G35, } \\
\text { G38, G39 }\end{array}$ & $\begin{array}{c}\text { Ulat } \\
\text { Penggorok } \\
\text { Daun }\end{array}$ & $\begin{array}{c}\text { Ulat } \\
\text { Penggorok } \\
\text { Daun }\end{array}$ & Sesuai \\
\hline 40. & $\begin{array}{l}\text { G06, G07, } \\
\text { G08, G15, } \\
\text { G19, G22 }\end{array}$ & $\begin{array}{l}\text { Kanker } \\
\text { Batang }\end{array}$ & $\begin{array}{l}\text { Kanker } \\
\text { Batang }\end{array}$ & Sesuai \\
\hline 41. & $\begin{array}{l}\mathrm{G} 19, \mathrm{G} 23, \\
\mathrm{G} 24, \mathrm{G} 25\end{array}$ & Bercak Daun & Jamur Upas & $\begin{array}{l}\text { Tidak } \\
\text { Sesuai }\end{array}$ \\
\hline 42. & $\begin{array}{l}\text { G26, G27, } \\
\text { G28, G29 }\end{array}$ & Thrips & Babi Hutan & $\begin{array}{l}\text { Tidak } \\
\text { Sesuai }\end{array}$ \\
\hline 43. & $\begin{array}{l}\text { G20, G21, } \\
\text { G25, G31 }\end{array}$ & Bercak Daun & Bercak Daun & Sesuai \\
\hline 44. & $\begin{array}{l}\text { G01, G02, } \\
\text { G03, G06, } \\
\text { G07, G09, } \\
\text { G12 }\end{array}$ & $\begin{array}{l}\text { Kanker } \\
\text { Batang }\end{array}$ & $\begin{array}{l}\text { Kanker } \\
\text { Batang }\end{array}$ & Sesuai \\
\hline 45. & $\begin{array}{l}\text { G26, G27, } \\
\text { G28, G30 }\end{array}$ & Thrips & Babi Hutan & $\begin{array}{l}\text { Tidak } \\
\text { Sesuai }\end{array}$ \\
\hline 46. & $\begin{array}{l}\text { G40, G41, } \\
\text { G42 }\end{array}$ & Kutu Putih & Kutu Putih & Sesuai \\
\hline 47. & $\begin{array}{l}\text { G12, G13, } \\
\text { G16, G17, } \\
\text { G20, G21, } \\
\text { G22 }\end{array}$ & Bercak Daun & Bercak Daun & Sesuai \\
\hline
\end{tabular}

Hasil Diagnosis

\begin{tabular}{|c|c|c|c|c|}
\hline \multirow{2}{*}{ No } & \multirow{2}{*}{ Gejala } & & \multirow{2}{*}{ Validas } \\
\hline & & Pakar & Sistem & \\
\hline 48. & $\begin{array}{l}\text { G30, G33, } \\
\text { G35, G36, } \\
\text { G37, G38 }\end{array}$ & $\begin{array}{c}\text { Ulat } \\
\text { Penggorok } \\
\text { Daun }\end{array}$ & $\begin{array}{c}\text { Ulat } \\
\text { Penggorok } \\
\text { Daun }\end{array}$ & Sesuai \\
\hline 49. & $\begin{array}{l}\text { G20, G21, } \\
\text { G22, G23, } \\
\text { G25, G26 }\end{array}$ & Bercak Daun & Bercak Daun & Sesuai \\
\hline 50. & $\begin{array}{l}\text { G05, G07, } \\
\text { G12, G13 }\end{array}$ & $\begin{array}{l}\text { Kanker } \\
\text { Batang }\end{array}$ & $\begin{array}{l}\text { Kanker } \\
\text { Batang }\end{array}$ & Sesuai \\
\hline
\end{tabular}

Hasil evaluasi sistem dengan menerapkan metode Certainty Factor didapatkan 40 data uji yang sesuai dan 10 data uji yang tidak sesuai dengan hasil diagnosis pakar. Maka nilai kesesuaian antara diagnosis pakar dan diagnosis sistem adalah seperti berikut : Banyak data uji $\times 100 \%$ $=\frac{40}{50} \times 100 \%=80 \%$

\section{KESIMPULAN DAN SARAN}

\section{IV.1 Kesimpulan}

Kesimpulan dari penelitian ini adalah seperti berikut :

1. Metode Certainty Factor dapat mendiagnosis penyakit dan hama pada tanaman manggis berdasarkan gejala-gejala yang ada.

2. Berdasarkan dengan kasus data uji yang sama terdapat sebanyak 10 hasil diagnosis sistem dengan menggunakan metode Certainty Factor yang berbeda dengan hasil diagnosis pakar. Perbedaan hasil diagnosis tersebut dikarenakan terdapat lebih dari satu penyakit dan hama yang menyerang tanaman manggis.

\section{IV.2 Saran}

Saran yang dapat diberikan pada penelitian Sistem Pakar Diagnosis Penyakit dan Hama Tanaman Manggis berbasis web adalah :

Farha Fitrahul Janah, Gibtha Fitri Laxmi, Freza Riana 
1. Untuk meningkatkan keakuratan data disarankan menambahkan beberapa pakar agar hasil diagnosis lebih akurat.

2. Sistem dapat dikembangkan menjadi aplikasi mobile agar lebih mudah diakses oleh siapapun.

3. Dapat menambahkan atau menggabungkan beberapa metode dalam proses diagnosis penyakit dan hama tanaman manggis.

\section{REFERENSI}

Andriani, A. (2016) "Pemrograman Sistem Pakar," in Taqwih (ed.) Pemrograman Sistem Pakar. 1 ed. MediaKom, hal. 9.

Anwarudin, J. (2016) Untung Berlipat Dari Budidaya Manggis Tanaman Multi Manfaat. 1 ed. Diedit oleh Maya. Yogyakarta: Lily Publisher.

Arifin, M., Eka, W. dan Retnani, Y. (2017) "Penerapan Metode Certainty Factor Untuk Sistem Pakar Diagnosis Hama Dan Penyakit Pada Tanaman Tembakau."

Fanny, R. R., Hasibuan, N. A. dan Buulolo, E. (2017) "Perancangan Sistem Pakar Diagnosa Penyakit Asidosis Tubulus Renalis Menggunakan Metode Certainty Factor Dengan Penelusuran Forward Chaining," Media Informatika Budidarma, 1(1), hal. 13-16.

Firdaus, Di. (2011) Manggis (Garcinia mangostana L), Litbang Pertanian. Tersedia pada: https://jabar.litbang.pertanian.go.id/index.p hp/info-teknologi/14-alsin/64.

Hayadi, B. H. (2016) Sistem Pakar. 1 ed. Yogyakarta: Deepublish.

Kusrini (2008) Aplikasi Sistem Pakar Menetukan Faktor Kepastian Pengguna Dengan Metode Kuantifikasi Pertanyaan. Diedit oleh D. Prabantini. Indonesia: CV Andi Offset. Tersedia pada: https://books.google.co.id/books?id=eVLp MIoxq8IC\&lpg=PP1\&hl=id\&pg=PP4\#v=0 nepage $\& q \& \mathrm{f}=$ false.

Muslim, C. (2011) “( Studi Kasus di Kabupaten Purwakarta , Jawa Barat ) Competitiveness of Mangosteen: Export Promotion , Marketing System , and Stability in Domestic Market ( A Case Study in Purwakarta Regency, West Java province )," hal. 87-111.

Saputri, A. E. et al. (2020) "Using Certainty Factor Method to Handle Uncertain Condition in Hepatitis Diagnosis," ComTech: Computer, Mathematics and Engineering Applications, 11(1), hal. 1-10. doi: 10.21512/comtech.v11i1.5903. 